\section{Familial craniofacial fibrous dysplasia: absence of linkage to GNAS1 and the gene for cherubism}

EDITOR-Fibrous dysplasia is a benign fibro-osseous condition that may involve one or more bones in the cranial and extracranial skeleton. There are four main types of fibrous dysplasia: monostotic in which only one bone is affected $^{1}$; polyostotic in which multiple bones are affected ${ }^{2}$; McCune-Albright syndrome (MIM 174800), a polyostotic form accompanied by pigmentation lesions and endocrine dysfunction presenting as precocious puberty in females ${ }^{3}$; and a craniofacial form (CFD) in which only bones of the craniofacial complex are affected. ${ }^{5}$ The majority of patients with CFD present in their second decade; the lesions are generally unilateral and tend to become static once skeletal maturity is reached. ${ }^{6}$

Fibrous dysplasia usually occurs with no family history, although CFD has been shown to be inherited in an autosomal dominant fashion. ${ }^{7}$ Activating mutations within the guanine nucleotide binding protein gene (GNAS1) (MIM 139320), located on chromosome 20q13.2-13.3, ${ }^{9}$ have been identified in lesions from monostotic fibrous dyspla$\mathrm{sia}^{10}$ polyostotic fibrous dysplasia, ${ }^{11}{ }^{12}$ and McCuneAlbright syndrome. ${ }^{13}$ At present it is unknown whether this gene is mutated in the germline of patients with familial CFD.

Another candidate gene for CFD is the gene responsible for cherubism (MIM 118400), recently localised to a $3 \mathrm{cM}$ interval on the telomere of chromosome $4 \mathrm{p} .{ }^{14}{ }^{15}$ Cherubism is a hereditary fibro-osseous lesion of the jaw, but in contrast to CFD the disease presents in the first decade of life and involves the mandible and maxilla bilaterally. However, like CFD, cherubism stabilises and largely resolves with skeletal maturity.

As the gene for familial CFD has not been identified, we have studied a family with the disease, which has been under observation for over 20 years. ${ }^{816}$ The family was interviewed and samples were collected with full informed consent of the patients involved and with local Ethical Review Board approval. DNA was extracted from peripheral venous blood samples using conventional methods. Polymorphic microsatellite markers were PCR amplified and electrophoresed through $4 \%$ denaturing polyacrylamide gels on a conventional gel system. One PCR primer was end labelled using T4 polynucleotide kinase and $\gamma^{32}$ PATP and the gel was exposed to autoradiography film for 1-16 hours.

Two point and multipoint linkage analyses were carried out using the MLINK suite of programs. A model was used in which disease alleles were given a frequency of 0.0001 , the penetrance was set at $90 \%$, and no sporadic cases were allowed.

Ten polymorphic microsatellite markers from the telomeric region of $4 \mathrm{p}$ and two markers flanking the GNAS1 gene were used to generate haplotypes from these regions. The marker order and sex averaged genetic distances in $\mathrm{cM}$ within the chromosome 4 interval from the Genethon map are 4pter - D4S2936, D4S3038 - 1.8 - D4S1614-1.9 D4S3034, D4S412. Using additional information and mapping data from the current studies the following order has been reached 4pter - D4S2936, D4S3038 - PDE6B D4S3360 - D4S1614 - D4S43 - D4S127 - HD - D4S3034, D4S412. The chromosome 20 Genethon map places the two markers D20S171 - 2.1 - D20S173. The Genetic Location Database has ordered these two markers flanking GNAS1.

Two point lod scores (table 1) confirmed that there is no strong evidence to suggest linkage to chromosome 4p16.3. While D20S171 produced a highly negative lod score, D20S173 produced a positive lod score which may indicate the presence of a recombination event. However, as the affected subjects do not appear to inherit the same haplotype (fig 1), the result at D20S173 was probably because of an allele frequent in the population.

Three point lod scores of -4.79 using D4S3360 and the HD trinucleotide repeat and -5.23 using D20S171 and D20S173 were obtained.

The same somatic mutation ( $\operatorname{Arg}^{201}$ to His or Cys) has been found in lesions from monostotic fibrous dysplasia, polyostotic fibrous dysplasia, and McCune-Albright syndrome. ${ }^{1011} 13$ This indicates that these disorders share the same pathogenesis, with the mutation occurring at different stages of development, resulting in the varying extent of tissue involvement. The effect of these activating mutations is to increase the cAMP levels with the follow on effect of increasing Fos expression. ${ }^{11}$ Our data indicate that mutations in GNAS1 are not involved in the development of familial CFD, although of course it remains possible that the genetic cause is within another gene involved in the same regulatory pathway.

Distinguishing clinically between cherubism and CFD may be difficult if the skeletal abnormalities are localised to

Table 1 Two point lod scores

\begin{tabular}{|c|c|c|c|c|c|c|c|c|c|}
\hline & \multicolumn{9}{|l|}{$\theta$} \\
\hline & 0.0 & 0.05 & 0.1 & 0.15 & 0.2 & 0.25 & 0.3 & 0.35 & 0.4 \\
\hline $\mathrm{D} 4 \mathrm{~S} 2936$ & -0.69 & -0.48 & -0.33 & -0.22 & -0.14 & -0.08 & -0.04 & -0.01 & 0.00 \\
\hline $\mathrm{D} 4 \mathrm{~S} 3038$ & -1.46 & -0.76 & -0.49 & -0.34 & -0.24 & -0.17 & -0.12 & -0.08 & -0.05 \\
\hline PDE6B & -4.20 & -0.81 & -0.52 & -0.36 & -0.25 & -0.17 & -0.11 & -0.07 & -0.04 \\
\hline $\mathrm{D} 4 \mathrm{~S} 3360$ & -3.96 & -2.03 & -1.53 & -1.18 & -0.92 & -0.70 & -0.52 & -0.37 & -0.23 \\
\hline $\mathrm{D} 4 \mathrm{~S} 43$ & -4.31 & -1.31 & -0.91 & -0.67 & -0.49 & -0.36 & -0.25 & -0.17 & -0.10 \\
\hline D4S 1614 & 0.12 & 0.10 & 0.08 & 0.07 & 0.05 & 0.04 & 0.02 & 0.01 & 0.01 \\
\hline $\mathrm{D} 4 \mathrm{~S} 127$ & 0.37 & 0.32 & 0.27 & 0.22 & 0.17 & 0.13 & 0.08 & 0.05 & 0.02 \\
\hline HD & -5.52 & -1.74 & -1.20 & -0.87 & -0.63 & -0.45 & -0.31 & -0.20 & -0.11 \\
\hline $\mathrm{D} 4 \mathrm{~S} 3034$ & 0.43 & 0.37 & 0.32 & 0.26 & 0.20 & 0.15 & 0.10 & 0.06 & 0.03 \\
\hline $\mathrm{D} 4 \mathrm{~S} 412$ & -3.81 & -0.24 & -0.03 & 0.05 & 0.08 & 0.08 & 0.07 & 0.05 & 0.03 \\
\hline $\mathrm{D} 20 \mathrm{~S} 171$ & -4.11 & -2.02 & -1.35 & -0.95 & -0.68 & -0.48 & -0.32 & -0.20 & -0.11 \\
\hline D20S173 & 0.82 & 0.76 & 0.69 & 0.62 & 0.55 & 0.47 & 0.39 & 0.30 & 0.21 \\
\hline
\end{tabular}


A

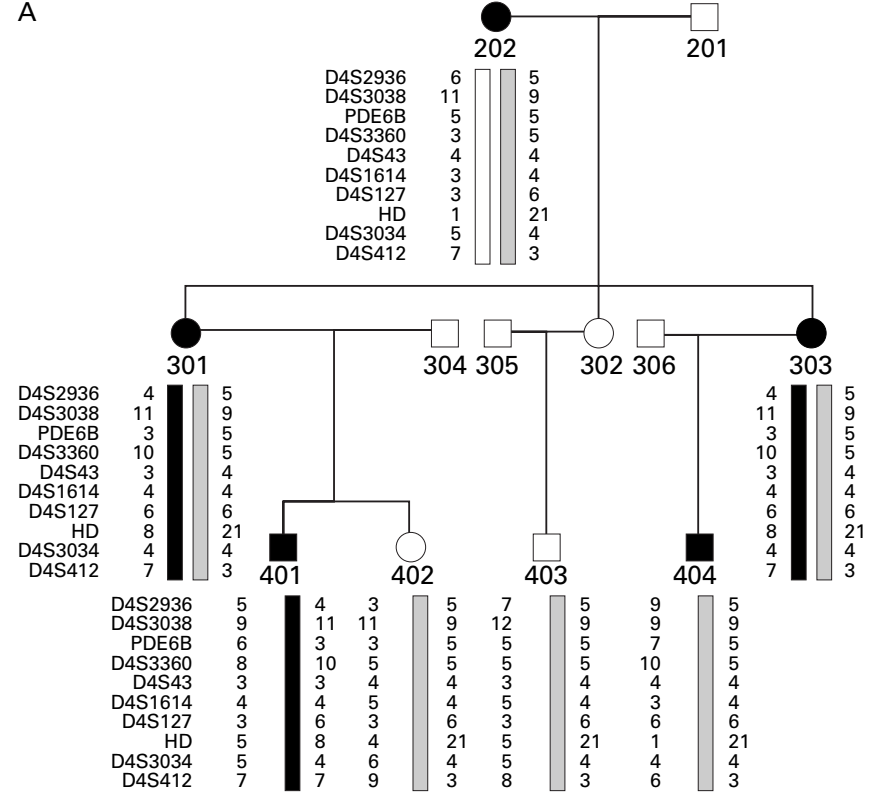

B

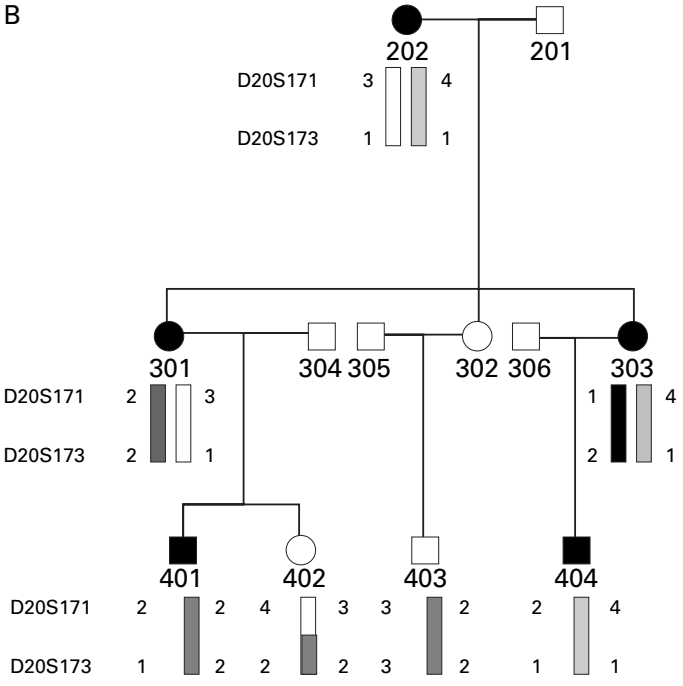

Figure 1 Pedigrees showing the haplotypes on (A) chromosome 4p16.3 and (B) chromosome 20q13.3.

the jaw, a problem highlighted by Zohar et $a l^{17}$ who reported that two members of the family have been diagnosed as having cherubism, whereas a third member was diagnosed as having fibrous dysplasia of the jaw. The differential between the two is further complicated as cherubism has been found to present as a unilateral disease and in early adolescence. ${ }^{18}$ The finding that this family does not map to the interval containing $C R B M$ shows that CFD and cherubism are distinct entities and provides for the first time a means of separating the two diseases.

Our results show that using linkage analyses, familial CFD does not result from mutations in CRBM or GNAS1. Therefore, on a molecular basis, CFD is a different entity from other forms of fibrous dysplasia and cherubism.

Electronic database information: Genethon map: http:// carbon.wi.mit.edu:8000/ftp/distribution/human_STS_releases/july97/genmap/ (for genetic maps). Genetic Location Database: http:// cedar.genetics.soton.ac.uk/public html/summaryml.html (for physical and gehttp://www ncbi.nlm nih gov/Omim (for cherubism (MIM 118400), GNAS1 (MIM 139320), McCune-Albright syndrome (MIM 174800)). We would like to thank the family for their enthusiastic help and encouragement. The samples were collected and prepared by the Department of Molecular Pathology, Instiwere collected and prepared by the Department of Molecular Pathology, Instiwas supported by the Cancer Research Campaign and the Institute of Cancer was supporte
Research.

\section{JONATHAN MANGION* SARAH EDKINS $\star$ ALASTAIR N GOSS + MICHAEL R STRATTON ${ }^{\star}$ ADRIENNE M FLANAGAN}

* Section of Cancer Genetics, Haddow Laboratories, Institute of Cancer Research, 15 Cotswold Road, Sutton, Surrey SM2 5NG, UK †Oral and Maxillofacial Surgery Unit, University of Adelaide, Adelaide, South Australia 5005

$\ddagger$ Department of Histopathology, Imperial College School of Medicine at St Mary's, Norfolk Place, London W2 1PG, UK

Correspondence to: Dr Mangion, jonm@icr.ac.uk
1 Lichtenstein L, Jaffe HL. Fibrous dysplasia of the bone. Arch Pathol 1942;33:777-816.

2 Lichtenstein L. Polyostotic fibrous dysplasia. Arch Surg 1938;36:874-98.

3 Albright F, Butler AM, Hampton AO, Smith P. Syndrome characterized by osteitis fibrosa disseminata, areas of pigmentation and endocrine dysfunction, with precocious puberty in females. N Engl f Med 1937;216:727-46.

4 McCune DJ. Osteitis fibrosa cystica: the case of a nine year old girl who also exhibits precocious puberty, multiple pigmentation of the skin and hyperthyroidism. Am $\mathcal{F}$ Dis Child 1936;52:743-4.

5 Daves ML, Yardley JH. Fibrous dysplasia of bone. Am $\mathcal{F}$ Med Sci 1952;234: 590-606.

6 Cooke BED. Benign fibro-osseous enlargements of the jaws. $\mathrm{Br}$ Dent $\mathcal{F}$ 1957;102:1-14.

7 Reitzik M, Lownie JF. Familial polyostotic fibrous dysplasia. Oral Surg Oral Med Oral Pathol 1975;40:769-74.

8 Pierce AM, Wilson DF, Goss AN. Inherited craniofacial fibrous dysplasia. Oral Surg Oral Med Oral Pathol 1985;60:403-9.

9 Levine MA, Modi WS, O'Brien SJ. Mapping of the gene encoding the alpha subunit of the stimulatory G protein of adenylylcyclase (GNAS1) to 20q13.2-q13.3 in humans by in situ hybridization. Genomics 1991;11:4789.

10 Shenker A, Chanson P, Weinstein LS, Chi P, Spiegel AM, Lomri A, Marie PJ. Osteoblastic cells derived from isolated lesions of fibrous dysplasia contain activating somatic mutations of the Gs alpha gene. Hum Mol Genet 1995;4:1675-6.

11 Candeliere GA, Glorieux FH, Prud'homme J, St-Arnaud R. Increased expression of the c-fos proto-oncogene in bone from patients with fibrous dysplasia. N Engl f Med 1995;332:1546-51.

12 Kitoh H, Yamada Y, Nogami H. Different genotype of periosteal and endosteal cells of a patient with polyostotic fibrous dysplasia. F Med Genet 1999; 36:724-5.

13 Weinstein LS, Shenker A, Gejman PV, Merino MJ, Friedman E, Spiegel AM. Activating mutations of the stimulatory G protein in the McCuneAlbright syndrome. N Engl F Med 1991;325:1688-95.

14 Mangion J, Rahman N, Edkins S, Barfoot R, Nguyen T, Sigurdsson A, Townend JV, Fitzpatrick DR, Flanagan AM, Stratton MR. The gene for cherubism maps to chromosome 4p16.3. Am f Hum Genet 1999;65:151-7.

15 Tiziani V, Reichenberger E, Buzzo CL, Niazi S, Fukai N, Stiller M, Peters $\mathrm{H}$, Salzano FM, Raposo do Amaral CM, Olsen BR. The gene for cherubism maps to chromosome 4p16. Am f Hum Genet 1999;65:158-66.

16 Pierce AM, Sampson WJ, Wilson DF, Goss AN. Fifteen-year follow-up of a family with inherited craniofacial fibrous dysplasia. F Oral Maxillofac Surg 1996;54:780-8.

17 Zohar Y, Grausbord R, Shabtai F, Talmi Y. Fibrous dysplasia and cherubism as an hereditary familial disease. Follow-up of four generations. $\mathcal{F}$ Craniomaxillofac Surg 1989;17:340-4

18 Reade PC, McKellar GM, Radden BG. Unilateral mandibular cherubism: brief review and case report. Br f Oral Maxillofac Surg 1984;22:189-94. 